\title{
JUURNAL_RU
}

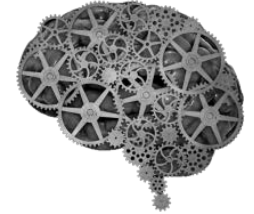

COMPANY GROUP "INTELLEKT"

\author{
Евсюков Д.В. \\ Волгоградский государственный университет \\ Волгоград, Россия
}

doi: 10.18411/lj2016-3-53

\section{Материальная мотивация персонала на базе целевого управления в виде системы KPI}

Стратегии развития всех современных компаний предусматривают и рост объемов производства, и повышение качества продукции и услуг. Поэтому одной из самых основных функций менеджера любого уровня является мотивация своих подчиненных на эффективную работу. Однако система мотивации, действующая в той или иной организации, должна не только побуждать персонал к активизации своей деятельности, но и должна взаимоувязывать цели обеих сторон. То есть она должна быть направлена на достижение целей организации, учитывая интересы всех сотрудников. В этом случае, она, как правило, должна базироваться на определенных показателях, которые сотрудники должны достичь. И такой эффект может быть получен за счет применения целевого управления и разработки на основе этого системы материальной мотивации.

Начало целевого управления было положено еще в 1950-х гг. в трудах Питера Друкера и Дугласа МакГрегора, а также в рамках концепции, разработанной Эдвином Локом. Он в 1968 г. первый опубликовал статью, в которой указал зависимость между мотивацией и целеполаганием сотрудников организации. [2, с.288].

Теория постановки целей Эдвина Лока подтверждается результатами исследования, проведенного с целью определения результативных сотрудников 
и поиска оптимальных методов мотивации, в котором приняли участие руководители и сотрудники более тысячи компаний, и опубликованного в 2004 г. в журнале Harvard Business Review. Оказалось, что в среднестатистической компании 5\% сотрудников всегда работают хорошо, столько же (5-7\%) сотрудников всегда работаю плохо, а для эффективной работы остальных 88\% всегда требуется правильная постановка целей и задач с обязательным контролем их исполнения. $[1, \mathrm{c.5}]$. Отсюда и следует, что внедрение в компании системы материальной мотивации на базе целевого управления в виде ключевых показателей эффективности (KРI) при соблюдении определенных условий и принципов может существенно повысить производительность и эффективность труда работников.

Зарубежный опыт убедительно доказывает, что внедрение системы КРI и мотивация персонала, построенная корректным образом, увеличивает прибыль компаний до $30 \%$ [3]. Сегодня уже многие российские компании активно внедряют систему КРI в управлении мотивацией и оценки эффективности работы персонала (рис. 1).
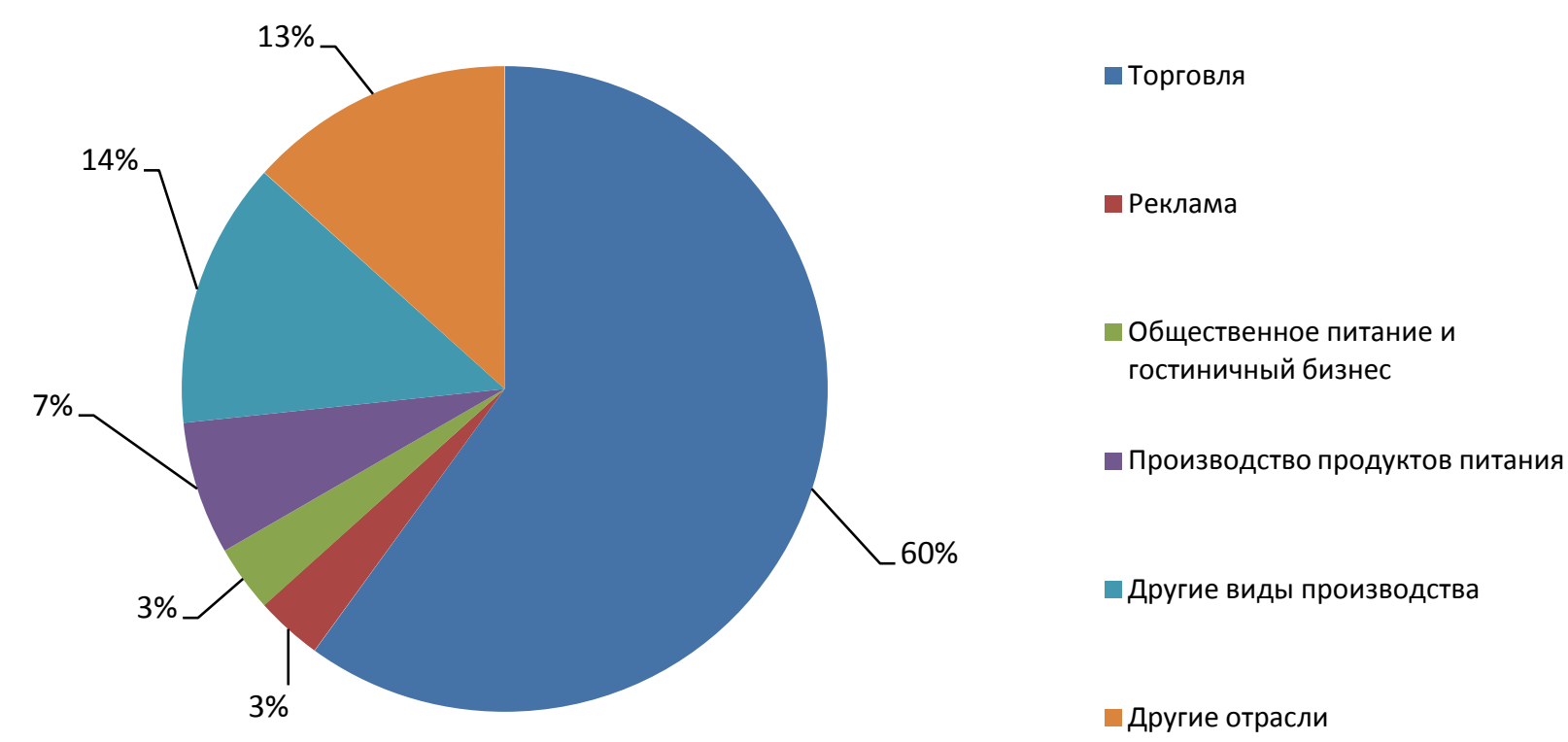

Puc. 1. Применение системы КРI в различных сферах деятельности. Источник: URL: https://kpi-drive.ru/ 
В настоящее время целевое управление в виде системы КРI представлено в качестве специальных компьютерных программ. Зайдя в данную программу, сотрудник компании может увидеть перечень своих ключевых показателей эффективности, их вес и фактическую и плановую степень выполнения в виде различных графиков и таблиц (рис. 2).

\begin{tabular}{|c|c|c|c|c|c|c|c|c|c|}
\hline $0=-$ & Thก & 2 & $\checkmark$ & Boe & & Eec & План & Факт & \% вьाП. \\
\hline$\theta$ & $\nabla$ & \multicolumn{3}{|c|}{ [ Заработная плата } & - & & 70000.00 & 73530.58 & 105.04 \\
\hline$\theta$ & $D$ & \multicolumn{3}{|c|}{ Окпад } & - & 0 & 28000.00 & 38000.00 & 135.71 \\
\hline Q & $B$ & \multicolumn{3}{|c|}{ Претии: } & - & o & 42000.00 & 35530.58 & 84.60 \\
\hline$\bigcirc$ & $D$ & \multicolumn{3}{|c|}{ - Результативность } & - & & 100.00 & 84.60 & $\mathbf{8 4 . 6 0}$ \\
\hline 8 & $D$ & $\mp$ & \multirow{2}{*}{\multicolumn{2}{|c|}{$\begin{array}{l}\text { Задачи } \% \\
\text { Оценка руководителя }\end{array}$}} & - & 20 & 100:00 & $79: 00$ & 79.00 \\
\hline$\theta$ & $D$ & + & & & - & 5 & 100.00 & 100.00 & 100.00 \\
\hline$\bigcirc$ & $\nabla$ & \multicolumn{3}{|r|}{$\begin{array}{l}\text { Копичество проданных } \\
\text { новьх А.м }\end{array}$} & - & 10 & 144.00 & 124.00 & 86.11 \\
\hline 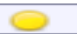 & $B$ & \multicolumn{3}{|r|}{ ПИМит расходов } & - & 15 & & & 87.88 \\
\hline$\bigcirc$ & $\nabla$ & \multicolumn{3}{|r|}{$\begin{array}{l}\text { OБъен вход аше по } \\
\text { трафика }\end{array}$} & - & 10 & 10000.00 & 7827.00 & 78.27 \\
\hline 8 & $D$ & \multicolumn{3}{|r|}{ Прибыль по предприатию } & - & 25 & & & 102.96 \\
\hline$\bigcirc$ & $D$ & \multicolumn{3}{|r|}{$\begin{array}{l}\text { Прирост оборотных } \\
\text { средств ОоО }\end{array}$} & - & 15 & & & 56.24 \\
\hline$\theta$ & $D$ & \multicolumn{3}{|c|}{ ФOT } & - & 0 & & & 115.51 \\
\hline
\end{tabular}

Pис. 2. Пример реализации модели КРІ - ключевые показатели эффективности Источник: URL: https://kpi-drive.ru/

Таким образом, можно сделать вывод, что система материальной мотивации персонала и целевое управления в виде ключевых показателей эффективности, как два взаимосвязанных и взаимодополняющих процесса, не только определяют результативность работника, но и позволяют направить мотивационное воздействие на персонал в необходимое для организации русло. 


\section{Литература:}

1. Клочков, А.К. КРІ и мотивация персонала. Полный сборник практических инструментов [Текст] / А.К. Клочков. - М:Эксмо, 2010. - 103 с.

2. Петров, А.Н. Менеджмент. Учебник для бакалавров [Текст] / А.Н. Петрова. - М.: Юрайт, 2012. - 645 с.

3. Мотивация труда на результат //сайт компании «Агентство эффективности». URL: http://www.ft-group.ru/knowledge-base/staffmotivation/420/ (дата обращения 20.02.2016). 